\title{
Post-marketing surveillance (Phase IV drug studies)
}

\author{
A statement from the Research Committee
}

Several College members have been in touch with the Research Committee asking for advice on the conduct of Phase IV trials. This topic has been extensively debated at the Research Committee, and we thought it would be helpful to members to have some guidance notes.

\section{What are Phase IV trials?}

The development of a drug is divided into a number of stages which are listed below. The clinical development of a compound is lengthy (five to ten years) and complex.

Phase I

This stage involves clinic pharmacology in normal volunteers generating pharmacokinetic. metabolic and pharmacodynamic data. It usually involves around 100 subjects. Certain drugs, e.g. cytotoxics, will bypass this phase. This would be rare in psychiatry.

\section{Phase II}

Clinical investigation to confirm kinetics and dynamics in patients rather than volunteers. It will provide some evidence of efficacy and identify a likely dosage range. Up to 500 patients will be treated with the drug.

Phase III

Formal therapeutic trials where efficacy will be established and evidence of safety obtained. It may involve 1,000 to 3,000 patients. Once these trials are complete, all pre-clinical, pharmaceutical and clinical data will be submitted as an application to the regulatory authority for a licence to sell the drug.

Phase IV

Phase IV trials are those which occur once the drug has a product licence and is available for regular prescription. The ostensible purpose of such trials is to assess the safety and side effects of the new drug, when it is available to the general population. It will then be prescribed to a much wider range of patients, and under a wider range of conditions than in a tightly controlled clinical (Phase III) trial.

Phase V

In addition to post-marketing survelllance, further clinical studies take place after a new drug is in widespread clinical use. Such trials (sometimes referred to as Phase $\mathrm{V}$ studies) are designed to evaluate efficacy and safety relative to other marketed compounds, and to explore new indications for the drug. Reformulation to allow a more convenient dosing schedule may take place at this time.

\section{What is the value of Phase IV studies?}

The Research Committee believes that such trials do have an important place, if they are conducted properly. Post-marketing surveillance is important, and the yellow card procedure has many drawbacks. In an ideal world, we would like to see more systematic post-marketing studies, either centrally funded or organised on a collaborative basis between drug companies. However, in the meantime, it is important that information is collected on a new drug and that if doctors are to spend their time carrying out such studies, they should be appropriately reimbursed.

Such studies have a deservedly bad reputation, because of the conduct of several drug companies in this area. There is not doubt that in some circumstances in the past, some of these studies have been little more than cynical marketing exercises, with doctors being paid either in cash or in kind to prescribe a drug for a patient or series of patients. It is for this reason that the guidelines referred to below have been published.

Members who are approached to carry these out should be aware of the guidelines on postmarketing surveillance, which were published under a 'Contemporary Themes' article in the BMJ on 6 February 1988 (volume 216). These were produced by a joint committee of the Association of the British Pharmaceutical Industry (ABPI), the British Medical Association (BMA), the Committee on Safety of Medicines (CSM) and the Royal College of General Practitioners. 
Nineteen separate points are made in the document; I have highlighted just a few of them here.

1. There should be valid medical reasons for undertaking such a study. The design and methods used must permit the achievement of the stated scientific and medical objectives. The study must not be designed for or conducted as a promotional exercise.

2. Where a study is prospective, patients should be identified for inclusion in the study, only after the decision has been made to prescribe a particular medicine.

3. The design, conduct and analysis of the study should originate in the company's medical department, and be under the supervision of a medical practitioner registered in the UK, and his or her name should be recorded on all documentation.

4. Drug representatives should not be involved in such a way that the study could be seen as a promotional exercise.

5. Remuneration - no inducement to undertake a study should be offered to, requested by, or given to a doctor participating in a company-sponsored postmarketing surveillance study. A scale of fees has been drawn up by the ABPI and BMA. In 1989 terms, these amounted to
$£ 5.40$ per completed form and $£ 10.80$ if the form was particularly complex.

It is suggested that any adverse reaction during a drug trial should be reported to the Committee on Safety of Medicine (Mkt Twrs, 1 Nine Elms Lane, London SW8). You may also wish to report to the National Drugs Advisory Board (Charles Lucas House, 63/64 Adelaide Road, Dublin 2).

More recently concern has been expressed about the practice of paying researchers on a per capita basis for patients recruited into other forms of clinical trials. Members are cautioned against undertaking such a contract in view of the danger that researchers would be placed under considerable pressure to recruit patients on grounds other than those required for the proper conduct of the trial.

We would recommend all Members and Fellows who are approached about PMS studies to read the guidelines referenced above. If you have any concerns about such studies, the Research Committee would be pleased to hear about them. You may also wish to write to the code of practice committee of the Association of the British Pharmaceutical Industry, 12 Whitehall, London SW1A 2DY.

C. P. Freeman, Chairman, Research Committee, Royal College of Psychiatrists

\section{Regional meeting}

A regional meeting of the Royal College of Psychiatrists will take place in the Middle East from 11-13 May 1994. Further information:
Dr N. Loza, Behman Hospital, Helwan, Cairo, Egypt (fax 202 960999).

\section{MRCPsych Part 1 and Part 2 examinations}

I would be grateful if all those concerned with the examination would note that as from April 1994, as already announced, candidates will be expected to be familiar with ICD-10.
Dr Sheila A. Mann, Chief Examiner, Royal College of Psychiatrists 